\title{
Dermatoglyphic and Cheiloscopic Patterns among Diabetic Patients: A Study in Ahmadu Bello University Teaching Hospital Zaria, Nigeria
}

\author{
Uduak E Umana (Corresponding author) \\ Department of Human Anatomy, Ahmadu Bello University, Zaria, Nigeria.
}

Tel: 234-803-701-5363Ｅmail: ueumana@abu.edu.ng

Ronke Bello

Department of Human Anatomy, Ahmadu Bello University, Zaria, Nigeria

Tel: 234-706-493-4702 E-mail: bolajifatimoh@yahoo.com

James Timbuak

Department of Human Anatomy, Ahmadu Bello University, Zaria, Nigeria Tel: 2348036986537 E-mail: jamesyne@yahoo.com

Augustine Ibegbu

Department of Human Anatomy, Ahmadu Bello University, Zaria, Nigeria Tel: 234-803-218-8042 E-mail: aoibegbu@yahoo.com

Sunday A. Musa

Department of Human Anatomy, Ahmadu Bello University, Zaria, Nigeria

Tel: 2348060901598 E-mail: samusa@abu.edu.ng

Daniel Ikyembe

Department of Human Anatomy, Ahmadu Bello University, Zaria, Nigeria

Tel: 2348069610005 E-mail: dtikyembe@ gmail.com 
Wilson Oliver Hamman

Department of Human Anatomy, Ahmadu Bello University, Zaria, Nigeria

Tel: 234-806-230-3007Ｅ-mail: hammanow@abu.edu.ng

Received: March 20, 2013 Accepted: April 2, 2013

doi:10.5296/jbls.v4i2.3399 URL: http://dx.doi.org/10.5296/jbls.v4i2.3399

\begin{abstract}
Dermatoglyphics has proved to be a very useful tool used for identification of many gene-linked abnormalities and diseases. Lip prints which as dermatoglyphics are unique to individuals have also been shown to be a useful genetic marker in some congenital and clinical diseases. The aim of this study was to determine the association between finger and lip prints patterns and diabetes mellitus using subjects in Zaria, Nigeria. 277 were examined: 101 diabetics and 126 normal subjects. The digital dermatoglyphic patterns were studied using method of Cummins while the lip prints were identified and classified according to method of Suzuki and Tsuchihashi. The results show that there is an association between finger print patterns of males with diabetes mellitus. The lip prints pattern of male and female diabetics also shows association with diabetes mellitus. From the study we could conclude that male with arch pattern of finger print in their right hand are at risk of developing diabetes also males with reticular pattern of lip prints have a higher risk of developing diabetes whereas those with intersected pattern have lesser chance of coming down with the disease. The result also shows that females with undifferentiated type of lip prints are at higher risk of developing diabetes.
\end{abstract}

Keywords: Lip prints patterns; Finger prints patterns, Association and Diabetes mellitus.

\title{
1. Introduction
}

Diabetes is a global disease and is increasing in occurrence. The prevalence of diabetes for all age-groups worldwide was estimated to be $2.8 \%$ in 2000 and to be $4.4 \%$ in 2030 (Wild et al., 2004), as such, investigators are looking for new methods for predicting its occurrence later in life and so as take preventive measure in other to reduce its onset. WHO projects that diabetes will be the 7th leading cause of death in 2030 (WHO, 2011). This has intensified the quest for further scientific understanding of the aetiology and pathogenesis of the disease; with the ultimate aim of improving its management. Studies are continuously being done in various fields of medicine to identify potential early biomarkers of diabetes. Finger and lip prints being genetically determined may serve as one of such biomarkers. Dermatoglyphics is the name given to the study of the ridges found on the fingers, palms and sole (Cummins and Midlo, 1961). Personal identification is becoming increasingly important not only in legal medicine but also in criminal investigation and identification; finger and lip prints are widely used for this. In anatomy, a fingerprint is a trace, print or scan of the friction ridges of the skin of any finger that serve as unique identification markers (Minkins, 2007). They are natural visible makers resulting from the thermodynamic processes during the early stages of human embryo 
formation and it has correlation with human character (Minkins, 2007). Finger print patterns can be classified according to Francis Galton into; Loop, Whorl and Arch (Galton, 1892). On the other hand, cheiloscopy is the study of lip prints, and lips prints are wrinkles and grooves present in the zone of transition of the lips (Saraswathie, 2009). Lip prints can be classified into the following types according to Tsuchihashi; Type I (Complete vertical), type IB (Incomplete vertical grooves), type II (Branched grooves), type III (Intersecting grooves), type IV (Reticular grooves), type V (Undifferentiating) (Tsuchihashi, 1974). This biological phenomenon was first noted by anthropologist Fischer in 1902, but it was based on the research done by two Japanese scientists Tsuchihashi and Suzuki that it was established that the arrangement of lines on the human lips is unique even in twins. They established that no two lip prints are identical (Suzuki and Tsuchihashi, 1970). Although various methods of Total Finger Ridge Count (TFRC) have been reported with contradicting results, researchers have been able to demonstrate that the ridge patterns are affected one way or the other by diabetes mellitus (Igbigbi et al., 2001). The objectives of the present study was to ascertain whether there is an association of finger print and lip prints pattern with diabetics, the study also seeks to determine sex differences in the finger and lip prints patterns of diabetics and to compare finger and lip print patterns of diabetics and non diabetic subjects.

\section{Materials and Methods}

Ethical approval was obtained from the university ethical committee and informed consent also obtained from the study subjects. The study was carried out on 101 diabetic patients (33 males and 68 females) with clinical and laboratory confirmation attending diabetic clinic in Ahmadu Bello University Teaching Hospital (ABUTH), Zaria between January and October, 2012; and 126 healthy subjects (50 females and 76 males) with no familial history of diabetes were used as the control group. The procedure of taking the fingerprint and lip print patterns was explained to the patients. Subjects used were selected on the basis that they had no deformity in the zone of transition of their lip and in their fingers. A questionnaire with patient's biodata such as name, age, marital status, tribe disease condition and occupation was handed to the correspondents to fill. After this Cummins' method was used for fingerprints; which include the use of ink pad. This was done after cleaning of the two hands to avoid dirt from the hands. The fingers were pressed upon a stamp pad and impressed on a white duplicating paper; subjects were asked to roll their pads from one side of the nail to another to enable better clarity of the impressions. The fingerprint patterns on each finger were noticed and documented base on ridges and furrows (Cummins and Midlo., 1961). The prints were later screened with the aid of the magnifying hand lens to reveal the finger print pattern, in accordance with Cummins's method (Cummins and Midlo., 1961). The digital patterns were recorded as whorls (W), Loop (L) and Arch (A). For the lip prints, the subjects were made to sit in a relaxed position and after cleaning the lips; the lip prints was made on the glass slide in a single motion without applying any sticky substance. This was then developed by dusting fine carbon black powder with an ostrich brush and the type of the lip prints was studied using a magnifying hand lens (x5) (Suzuki and Tsuchihashi, 1970). Then the lip prints were studied carefully to reveal the furrows of the lip in bright light and classified according to Suzuki and Tsuchihashi (Suzuki and Tsuchihashi, 1970). The lip prints were divided into four quadrants and recorded as; 
Right Upper quadrant $\quad$ RU

Right lower quadrant $\quad \mathrm{RL}$

Left upper quadrant LU

Left lower quadrant LL

The pattern of Suzuki and Tsuchihashi was used in the presentation of the data, which include;

Type I: clear-cut grooves running vertically across the lip (complete vertical)

Type I: the grooves are straight but disappear half way instead of covering the entire breadth of the lip (incomplete vertical)

Type II: the grooves are branched

Type III: the grooves are reticular

Type IV: the grooves are intersected

Type V: the grooves do not fall into any of the types above and cannot be differentiated morphologically.

All data collected are presented as frequencies and percentages. Associations between the variables were tested using the Chi-square test for independence. A p-value of $<0.05$ was considered significant for all analysis. WinSTAT® for Microsoft $®$ Excel version 2012 was used for the statistical analysis.

\section{Results}

Table 1. Comparison of Finger prints pattern between the healthy subjects and diabetic patients.

\begin{tabular}{|c|c|c|c|c|}
\hline \multirow{2}{*}{ PATTERN } & \multicolumn{2}{|c|}{ RIGHT } & \multicolumn{2}{c|}{ LEFT } \\
\cline { 2 - 5 } & Normal & Diabetic & Normal & Diabetic \\
\hline Loop & $406(64.4 \%)$ & $313(61.9 \%)$ & $400(63.5 \%)$ & $305(60.4 \%)$ \\
\hline Whorl & $167(26.5 \%)$ & $130(25.8 \%)$ & $155(24.6 \%)$ & $119(23.7 \%)$ \\
\hline Arch & $57(9.1 \%)$ & $62(12.3 \%)$ & $75(11.9 \%)$ & $81(16.0 \%)$ \\
\hline
\end{tabular}

$X^{2}=3.120, \quad$ d.f $=2, \quad p=0.210, X^{2}=4.045 ;$ d.f $=2 ; p=0.132$

The above result shows that there was no association $(\mathrm{p}<0.05)$. The percentage of loop and whorl patterns was higher in the normal subjects while the percentage of arch was higher in diabetics. 


\section{Macrothink}

Journal of Biology and Life Science ISSN 2157-6076 2013, Vol. 4, No. 2

Table 2. Comparison of finger prints variability between healthy subjects and male diabetic patients

\begin{tabular}{|c|c|c|c|c|}
\hline \multirow{2}{*}{ PATTERN } & \multicolumn{2}{|c|}{ RIGHT } & \multicolumn{2}{c|}{ LEFT } \\
\cline { 2 - 5 } & Normal & Diabetic & Normal & Diabetic \\
\hline \multirow{2}{*}{ Loop } & $264(66.3 \%)$ & $97(58.8 \%)$ & $247(65.0 \%)$ & $104(63.0 \%)$ \\
\hline Whorl & $114(28.6 \%)$ & $45(27.3 \%)$ & $103(27.1 \%)$ & $40(24.2 \%)$ \\
\hline Arch & $20 \quad(5.0 \%)$ & $23(13.9 \%)$ & $30(7.9 \%)$ & $21(12.7 \%)$ \\
\hline
\end{tabular}

$X^{2}=13.25 ; \quad$ d.f $=2 ; p=0.001 \quad X^{2}=3.30 ; \quad$ d.f $=2 \quad p=0.192$

The above results shows that there is association on the right hand $(\mathrm{p}<0.05)$. The association found in the right hand was probably due to high difference between arch pattern of finger prints in the right hand between the diabetics (13.9\%) and normal subjects (5.0\%). In the left hand there was no association.

Table 3. Comparison between finger print of normal subject and female diabetic patients

\begin{tabular}{|c|c|c|c|c|}
\hline \multirow{2}{*}{ PATTERN } & \multicolumn{2}{|c|}{ RIGHT } & \multicolumn{2}{c|}{ LEFT } \\
\cline { 2 - 5 } & Normal & Diabetic & Normal & Diabetic \\
\hline Loop & $160(64.0 \%)$ & $216(63.5 \%)$ & $153(61.2 \%)$ & $201(59.1 \%)$ \\
\hline Whorl & $53(21.2 \%)$ & $85(25.0 \%)$ & $52(20.8 \%)$ & $79(23.2 \%)$ \\
\hline Arch & $37(14.8 \%)$ & $39(11.5 \%)$ & $45(18.0 \%)$ & $60(17.7 \%)$ \\
\hline
\end{tabular}

$\mathrm{X}^{2}=2.134, \quad$ d.f $=2 ; \quad \mathrm{p}=0.344 \quad \mathrm{X}^{2}=0.499 ; \quad \mathrm{f}=2 ; \mathrm{p}=0.779$

Table 3 shows there is no association between the finger print pattern and diabetes in both hands.

Table 4. Comparison of lip print pattern between normal subjects and diabetic patients

\begin{tabular}{|c|c|c|c|c|c|}
\hline TYPES & LONG VERTICAL & RETICULAR & BRANCHED & INTERSECTED & UNDIFFRENTIATED \\
\hline DIABETES & $22(5.5 \%)$ & $139(34.4 \%)$ & $181(44.8 \%)$ & $19(4.7 \%)$ & $43(10.6 \%)$ \\
\hline NORMAL & $34(6.8 \%)$ & $140(27.8 \%)$ & $270(53.6 \%)$ & $46\{9.1 \%)$ & $14(2.8 \%)$ \\
\hline
\end{tabular}


$\mathrm{X}^{2}=35.53, \quad$ d.f $=4 ; \quad(\mathrm{P}<0.001)$

The above result shows that there is an association between lip print pattern and diabetes $(\mathrm{p}<$ $0.001)$. Reticular (34.4\%) and undifferentiated type (10.6\%) of lip prints pattern were higher in diabetics than in the normal subjects $(27.8 \%)$ and $(2.8 \%)$ respectively while the intersected type has its percentage higher in normal subjects compared to diabetics. Long vertical (5.5\%) and branched $(44.8 \%)$ have percentages that truly represent their percentage in the normal population.

Table 5. Comparison of lip print pattern between normal subjects and male diabetic patients

\begin{tabular}{|c|c|c|c|c|c|}
\hline TYPES & Long vertical & Reticular & Branched & Intersected & Undifferentiated \\
\hline DIABETES & $2(1.5 \%)$ & $61(46.2 \%)$ & $55(41.7 \%)$ & $2(1.5 \%)$ & $12(9.1 \%)$ \\
\hline NORMAL & $10(3.3 \%)$ & $92(30.3 \%)$ & $157(51.7 \%)$ & $31(10.2)$ & $14(4.6 \%)$ \\
\hline
\end{tabular}

$\mathrm{X}^{2}=21.89 ; \quad$ d.f $=4 ; \quad \mathrm{P}(<0.001)$

The above result shows that there is an association $(\mathrm{P}<0.001)$ between lip print pattern in males and diabetes. Reticular $(46.2 \%)$ and undifferentiated $(9.1 \%)$ type of lip prints have their percentage higher in diabetics while intersected types has its percentage lower in diabetics $(1.5 \%)$ than in the normal subjects $(10.2 \%)$. The percentage of long vertical $(1.5 \%)$ and branched $(41.7 \%)$ type of lip prints gives a true representation of their percentage in the normal subjects.

Table 6. Comparison of lip print pattern between normal subjects and female diabetics patients

\begin{tabular}{|c|c|c|c|c|c|}
\hline TYPES & Long vertical & Reticular & Branched & Intersected & (Undifferentiated) \\
\hline DIABETES & $20(7.4 \%)$ & $78(28.7 \%)$ & $126(46.3 \%)$ & $17(6.3 \%)$ & $31(11.4 \%)$ \\
\hline NORMAL & $24(12.0 \%)$ & $48(24.0 \%)$ & $133(56.5 \%)$ & $15(7.5 \%)$ & $0(0.0 \%)$ \\
\hline
\end{tabular}

$X^{2}=29.031 ;$ d.f $=4, p(<0.05)$

The result above shows an association $(\mathrm{P}<0.05)$ between lip print pattern in females and diabetes. Reticular $(28.7 \%)$, undifferentiated $(11.4 \%)$ have a higher percentage in diabetics compared to their percentage in the normal subjects $(24.0 \%)$ and $(0 \%)$ respectively. Branched (46.3\%), long vertical $(7.4 \%)$, intersected $(6.3 \%)$ in the diabetics were less in frequency when compared to values from normal subjects.

\section{Discussion}

Lip prints and Finger prints form a pattern that is unique for each individual. Comparative study on relationship of Lip prints in diabetes patients is scanty in literature, thus the 
association of Lip prints and finger prints patterns in diabetes is very important in order to relate the sex differences with Finger and Lip print patterns in diabetics. Table 1; The finger print variability between healthy subject and patients with diabetes shows slight predominance of the loop pattern in the normal subjects $(64.4 \%$ and $63.5 \%)$ compare to in diabetics $(61.9 \%$ and $60.4 \%$ ) in both the right and left hands respectively. The predominance of the loop in the normal subjects over diabetics is insignificant. This also holds for the whorl pattern $(26.5 \%$ and $24.6 \%$ ) in the normal population, and in diabetics (25.8\% and $23.7 \%)$. The arch pattern shows a slight increase in percentage in diabetics (12.3\% and $16.0 \%)$ compared with that of the normal subjects $(9.1 \%$ and $11.1 \%)$ in both the right and left hands respectively. The differences in frequency that exist in both study groups are insignificant and this explains why there was no statistical significant association between diabetic and finger print pattern. The frequency for both diabetics and normal subjects approximated each other. In a similar study by Oladipo and Ogunnowo (2004) using Nigerian subjects they had a similar pattern in both diabetics and none diabetics and there was no significant difference in the digital patterns between the two groups (diabetics and non-diabetic). This study partially agrees with the work of Hossein and Nasser (2010) where the predominance of the loop was in the control group only (57\%) and whorl was dominant in diabetic group (50\%); however their study was restricted to type 1 diabetes only. It agrees with the works of Shield et al., (1995) found no significant differences between Normal and Diabetic patients with regard to digital pattern as well as total ridge count (TRC), ATD angle, a-d ridge count, a-d distance, b-c distance and position of axial triradius (t). Table 2 however shows there is an association between the finger print patterns of the right hand of the males with diabetes. In comparing the finger prints variability of the right hand between normal subjects and diabetic, the increase in percentage of loop pattern was (66.3\% and 58.8\%), whorl (28.6\% and $27.3 \%)$ and the arch pattern was (5.0\% and $13.9 \%)$ respectively. The marked differences that exist in the loop and arch patterns is probably responsible for the significant association that exist in this group, thus males with arch pattern in their right hand may have a higher chance of developing diabetes. Table 3; which showed the comparisons of finger prints pattern of normal subjects and female diabetic patients, with no statistical significant difference, between the two groups. This was in contrast with the research performed on Khoras and English diabetic women which shows an increase in arch forms in finger tips of diabetic women compared to the control group (Rezal et.al., 1999). Table 4; Comparing the lip prints of the normal subjects and Diabetic patients, The percentage of reticular and undifferentiated type of lip print pattern is significantly higher in diabetics $(34.4 \%$ and $10.6 \%)$ compared to the normal population $(27.8 \%$ and $2.8 \%$ ) respectively, this could indicate that people with this type of print are at a higher risk of developing diabetes mellitus while the intersected and branched type of lip prints shows a lower percentage in diabetics (4.7\% and $44.8 \%$ respectively) compared to the normal population ( $9.1 \%$ and $53.6 \%$ respectively), thus indicating a lower chance of developing diabetes by this group of people. Tables 5 and 6 examined the sex differences in lip pattern and both had a similar trend. In Table 5, reticular and undifferentiated type of lip prints shows a higher percentage in diabetics $(46.2 \%$ and $9.1 \%)$ compare to their percentage in the normal subjects $(30.3 \%$ and $10 \%)$ respectively while table 6 reticular and undifferentiated type was also higher in diabetics $(28.7 \%$ and $11.4 \%)$ compare to their percentage in the normal subjects $(24.0 \%$ and $0 \%)$ respectively. This shows that their 
percentage is not just by chance or as a result of their occurrence in the normal population but could be a true representation of their occurrence in the disease condition. In Table 5, the intersected pattern type shows lower percentages in male diabetics $(1.5 \%)$ compare to its percentage in the normal population $(10.2 \%)$ which indicate that male with this type will be at a lesser risk of developing diabetes. Table 6; Comparison of lip prints in the female diabetic patients and normal population the percentage of reticular and undifferentiated type was higher in diabetics $(28.7 \%$ and $11.4 \%)$ compared to their percentage in the normal subjects $(24.0 \%$ and $0 \%$ ) respectively. The frequency of undifferentiated print pattern is very significant here as none of the normal female subjects had it. Thus female with this pattern are at a significantly higher risk of developing diabetes and this probably explains the statistical association that exist in this group.

\section{Conclusion}

The study did not show any significant association between the finger print patterns and diabetes when analysed for both sexes together. It however demonstrated that there is an association in the finger prints pattern of the right hand in male diabetics. The study showed significant association between the lip print patterns in the overall population and for males and females cases separately. In the overall test population, the findings indicate that males with intersected type of lip prints patterns may have lesser chances of developing diabetes while those with reticular and undifferentiated are at a higher risk of developing diabetes. This study also shows that there is an association between undifferentiated type of lip prints with female diabetics compared to the normal population thus female with this type will be at a higher risk of developing the disease condition.

\section{Recommendation}

Since finger and lip prints hold a potential to serve as a supplementary tools, to predict the expectance of diabetes in an individual especially those with a family history of diabetes further studies should be carried out and larger samples should be examined in detail to further validate the findings of this study and come to definitive conclusion.

\section{References}

Galton, F. (1892). Finger print. London: Macmilian and co. Harold Cummins and Charles midlo. (1943). Finger prints, Palms and Soles an Introduction to Dermatoglyphics. Philadelphia: The Blakiston company.

Cummins H., \& C. Midlo. (1961). Fingerprints, Palms and Soles, an Introduction to Dermatoglyphics $2^{\text {nd }}$ edition (New York: Doves Publications Incorporated) pp: 121-124.

Fitch R. (2004). WinSTAT: Statistics Add-in for Microsoft Excel Software.

Hossein R. N., \& Nasser M. S. (2010). Application of Dermatoglyphic Traits for Diagnosis of Diabetic Type 1 Patients. International Journal of Environmental Science and Development, 1(1), 36-39. ISSN: 2010-0264

Igbigbi PS, \& Msati BC. (1999). Plantar and Digital Dermatoglyphics In Malawians. C. 
African Journal of Medicine. 45(10), 264-268.

Minkin, V. (2007). Dermatoglypics bases. St. Petersburg, Elsys Corp.

Oladipo G., \& Ogunnowo B. M. (2004). Dermatoglyphic patterns in diabetes mellitus in a south eastern Nigerian population, African Journal of Applied Zoology \& Environmental Biology. 6, 6-8. ISSN 1119-023X

Rezal F, Haddad F, \& Mahdavi Shahri N. (1999). A Report of Dermatoglyphics Characteristic in a Barbarian Populations Resident in Khorasian Province and its Application in Physical Anthropology, A Collection of Paper Abstract, Iranian First Congress on Applied Biology. Mashhad, Iran. 164.

Saraswathie, M. G. (2009). Study of Lip prints, Journal of Forensic Dental Science. 1, 28 -31. http://dx.doi.org/10.4103/0974-2948.50885

Shield J. P, Wadsworth E. J, Hobbs K, \& Baum J. D. (1995). Dermatoglyphics Jetal Growth, and diabetes in children. Archives of Disease in childhood, 72, 159-160. http://dx.doi.org/10.1136/adc.72.2.159

Suzuki K., \& Tsuchihashi Y. (1970). Personal identification by means of lip print. J. Forensic Med. 17(2), 52-57.

Suzuki K, \& Tsuchihashi Y. (1971). New Attempt for Personal Identification By Means of Lips prints, Journal of Forensic science, 45, 237-51.

Tsuchihashi Y. (1974): Studies on personal identification by means of lip prints. Forensic Sci. 3(3), 233-248. http://dx.doi.org/10.1016/0300-9432(74)90034-X

World Health Organization. (2011). Global status report on noncommunicable diseases 2010. Geneva

Wild. S., Gojka R., Anders G., Richard S., \& Hilary K. (2004). Global Prevalence of Diabetes Estimates for the year 2000 and projections for 2030, Diabetes Care, 27(5). http://dx.doi.org/10.2337/diacare.27.5.1047

\section{Copyright Disclaimer}

Copyright reserved by the author(s).

This article is an open-access article distributed under the terms and conditions of the Creative Commons Attribution license (http://creativecommons.org/licenses/by/3.0/). 